Magna Scientia Advanced Biology and Pharmacy

eISSN: $2582-8363$

Cross Ref DOI: $10.30574 / \mathrm{msabp}$

Journal homepage: https://magnascientiapub.com/journals/msabp/

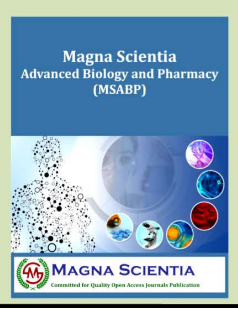

(REview ARTICLE)

\title{
A review of toxicology studies on mammals
}

\author{
Dunya Khalaf Hamad * \\ Prosthetics and Orthotics Engineering Department, Al-Nahrain University, Baghdad, Iraq.
}

Magna Scientia Advanced Biology and Pharmacy, 2021, 03(02), 022-026

Publication history: Received on 29 July 2021; revised on 06 September 2021; accepted on 08 September 2021

Article DOI: https://doi.org/10.30574/msabp.2021.3.2.0037

\begin{abstract}
Chlorinated cyanurates are added to swimming pools as disinfectants. In the presence of water, these materials hydrolyze to yield cyanurate and hypochlorous acid. To evaluate the safety of exposure to these materials, a comprehensive testing program was undertaken. This review summarizes the results of acute and subchronic tests on chlorinated isocyanurates. Findings from acute, subchronic, reproduction, metabolism, mutagenicity, and chronic/carcinogenicity tests on cyanurate are also summarized. Results from these tests indicate that chlorinated isocyanurates are safe for use in swimming pools.
\end{abstract}

Keywords: Chlorinated isocyanurates; Metabolism; Mutagenicity; Chronic/carcinogenicity tests

\section{Introduction}

Chlorinated derivatives of cyanurate and its salts (chlorinated isocyanurates) are used as disinfectants and algicides for swimming pools and cooling towers and are regulated under provisions of the Federal Insecticide, Fungicide and Rodenticide Act (FIFRA). These compounds are also used as cleansing, bleaching, and sanitizing agents in a variety of industrial applications. In the presence of water, chlorinated isocyanurates undergo hydrolysis to yield cyanurate and hypochlorous acid; the latter compound is an active bactericide and oxidizing agent. The cyanurate moiety stabilizes hypochlorite in the presence of sunlight, prolonging its disinfectant action in swimming pools.

The greatest potential for human exposure to cyanurate results from its use as a stabilizer of hypochlorite in swimming pools. Workers are also exposed to chlorinated isocyanurates during their manufacture and packaging. To assess the risks from such exposure, a variety of toxicology studies have been undertaken on both chlorinated isocyanurates and cyanurate. This review summarizes the results of published toxicity studies and unpublished information developed by member companies of The Industry Ad hoc Committee on Isocyanurates. All of the last educations have been giving into the U. S. Environmental Protection Agency.

\section{Toxicology Studies}

\subsection{Acute Toxicity}

Dichloro- and trichloroisocyanurates are considered no more than slightly toxic when administered as single oral doses in rats. The $\mathrm{LD}_{50}$ values range from 600 to $1520 \mathrm{mg} / \mathrm{kg}$. These materials are practically nontoxic when applied as a single dose to rabbit skin, since the dermal LD50 is consistently greater than $5000 \mathrm{mg} / \mathrm{kg}$ (Monsanto, unpublished observations). Chlorinated isocyanurates are generally corrosive when applied to the rabbit eye and are severely irritating or corrosive to rabbit skin when applied under occluded conditions for $24 \mathrm{hr}$. according to procedures

\footnotetext{
${ }^{*}$ Corresponding author: Dunya Khalaf Hamad

Prosthetics and Orthotics Engineering Department, Al-Nahrain University, Baghdad, Iraq. 
specified in the Federal Hazardous Substances Act (FHSA). However, when tested in the 4-hr Department of Transportation (DOT) test, these materials are not corrosive to rabbit skin (1)

\subsection{Subchronic Toxicity}

Several inhalation studies have been conducted with rats exposed to chlorinated isocyanurate dust. In an early study that provided little information on experimental details, the LC50 of trichloroisocyanurate dust was reported to be 25 $\mathrm{mg} / \mathrm{m} 3$ (2). As part of this investigation, $1.88 \mathrm{mg} / \mathrm{m} 3$ of the trichloroisocyanurate dust, administered $4 \mathrm{hr} / \mathrm{day}$ for 10 weeks, was reported to have caused 30\% mortality in rats. Findings from more recent inhalation studies with dichloroisocyanurate [3] and trichloroisocyanurate (Monsanto, unpublished observations) did not agree

with these result. In these studies, groups of 10 males and females CD rats were exposed separately to dichloroisocyanurate and trichloroisocyanurate dusts at analytical exposure levels of approximately 3, 10, and 30 $\mathrm{mg} / \mathrm{m} 3$ for $6 \mathrm{hr} /$ day, 5 days/week for a total of 4 weeks. The mass median diameter of chlorinated isocyanurate dusts ranged from 2.1 to 4.5 ,um (the material was sieved to produce respirable dust particles). Contrary to the earlier report, no mortality occurred in test animals in either of these two studies. Adverse reactions were observed in both of the recent studies in mid- and particularly high-dose animals during the exposure period and included moist rales, nasal discharge, excess salivation, lacrimation, and labored breathing. Because of the deposition of dust on rat fur, the rats undoubtedly ingested the test materials during preening. Apparent treatment-related changes were observed in body weights, organ weights, and certain clinical parameters in mid- and, especially, high-dose animals. However, these changes were not consistently observed in both studies with the exception of increased lung weights, which were observed in high-dose rats in both studies. No remarkable gross pathologic changes were observed in test animals sacrificed at the end of the study (4). Microscopic examination of tissues from high-dose animals did not reveal any changes that were attributed to treatment. (Animals administered trichloroisocyanurate dust were sacrificed 4 days after exposure had terminated). The lower exposure concentration of $3 \mathrm{mg} / \mathrm{m} 3$ was considered a no-effect level in both studies. The approximate daily dose of chlorinated isocyanurate dust administered to rats in these 2 studies was 0.64 $\mathrm{mg} / \mathrm{kg}$ for the lowest exposure level. This dose was calculated by assuming that total volume of air inspired by a rat over a $6 \mathrm{hr}$ exposure period is $0.086 \mathrm{~m} 3$. The comparable dose administered to a man (total volume of air inspired over $8 \mathrm{hr}$ is $10.4 \mathrm{im} 3$ ) exposed to $0.5 \mathrm{mg} / \mathrm{m} 3$ of chlorinated isocyanurate dust (a nonirritating level based on Monsanto workplace experience) can be estimated to be about $0.074 \mathrm{mg} / \mathrm{kg}$ (5). This exposure level is lower by a factor of 8 than the no-effect exposure level in the rat. Chlorinated isocyanurates have also been administered in the feed and drinking water of rats to evaluate their potential subchronic toxicity. In one study, dichloro- and trichloroisocyanurate were administered separately in drinking water to rats at concentrations of 0,400,1200, 4000, and 8000 ppm for 59 days (Industry ad hoc Committee, unpublished observations). Each treatment group consisted of five animals/sex/group except controls (ten/sex). Mortality and adverse signs (labored breathing, decreased activity) were observed in the 4000- and, especially, the 8000-ppm treatment groups administered dichloro- or trichloroisocyanurate. Animals in these groups also exhibited moderate to marked reductions in body weight, and in food and water consumption. (Water consumption was reduced in all treatment groups presumably because of unpalatability (6) Hematology, clinical chemistry, and urinalysis parameters were evaluated for all treatment groups at the end of the study. Most values were within historical limits although urine volume and urinary creatinine were reduced relative to control values for males administered 8000 ppm chlorinated isocyanurates. At necropsy, animals administered 8000 ppm chlorinated isocyanuratesexhibited an increased inci'dence of bleeding in the gastrointestinal tract. (No histopathology was performed on these animals.) With the exception of reduced drinking water consumption, administration of $400 \mathrm{ppm}$ (males) and 1200 ppm (females) of chlorinated isocyanurates did not cause observable adverse effects in test animals. This finding translates to no-effect doses ranging from approximately 50 to $130 \mathrm{mg} / \mathrm{kg}$, depending on the sex of the animals. In another subchronic study, dichloroisocyanurate was incorporated in the diet of albino rats at concentrations of $0,2000,6000$, and 12,000 ppm (Monsanto, unpublished observations). Groups of 10 animals/sex were administered these test diets for 13 weeks (7). Body weights and food consumption were reduced in the two highest treatment groups; mortality was limited to one high-dose female rat. Urinary and hematological parameters were unaffected by any of the treatments. Relative kidney and liver weights were increased for midand high-dose animals of both sexes. No dose-related, gross or microscopic pathologic changes were observed in any of the test animals. The no-effect level was considered to be $2000 \mathrm{ppm}$ dichloroisocyanurate, which is equivalent to a daily consumption of $100 \mathrm{mg} / \mathrm{kg}$ ( 8). 


\section{Toxicology Studies}

\subsection{Acute Toxicity}

Cyanuric acid is practically nontoxic when administered as a single oral or dermal dose. The oral LD50 in rats is greater than $10,000 \mathrm{mg} / \mathrm{kg}$; the dermal LD50 in rabbits is greater than $7940 \mathrm{mg} / \mathrm{kg}$. According to FHSA tests in rabbits, cyanuric acid is a slight eye irritant (1.5/110) and nonirritating to rabbit skin (Monsanto, unpublished observations) (9).

\subsection{Sub chronic Toxicity Studies}

The sub chronic toxicity of sodium cyanate has been evaluated in both CD rats and B6C3F1 mice (Industry ad hoc Committee, unpublished observations). In these studies, sodium cyanurate was administered at concentrations up to $5375 \mathrm{ppm}$ (maximum solubility limit for cyanurate). At this concentration, the daily compound consumption was 500 to $700 \mathrm{mg} / \mathrm{kg}$ for rats and 2000 to $2200 \mathrm{mg} / \mathrm{kg}$ for mice. The only adverse effect observed in test animals was the finding of bladder calculi with accompanying bladder epithelial hyperplasia in a few high-dose male rats and mice. This finding was not unexpected, since sodium cyanurate is not appreciably water soluble and precipitates to form calculi in urine at high concentrations. In a related study, sodium cyanurate was administered by gavage to F334 rats and B6C3F1 mice at doses ranging from 500 to $6000 \mathrm{mg} / \mathrm{kg} /$ day for 14 weeks (National Toxicology Program, private communication). At the higher treatment levels, it was unclear whether the test animals received the targeted dose levels. At these levels, the test material precipitated out of solution during dosing, making it difficult to deliver the desired dose quantitatively. There was no evidence of compound-related clinical changes and gross or microscopic lesions in the tissues of high dosage rats and mice (10).

\subsection{Chronic Toxicity}

Sodium cyanurate was administered in the drinking water of CD rats and B6C3F1 mice for most of their lifetime; e.g., 2 years (Industry ad hoc Committee, unpublished observations) (6). CD rats were randomly assigned to treatments of 80 to 100 /sex/group administered either $400,1200,2400$, or $5375 \mathrm{ppm}$ sodium cyanurate (maximum solubility level). An equal number of control animals received either tap water or sodium hippurate to provide an equivalent amount of sodium administered to high-dose cyanurate animals. Animals were observed regularly for adverse reactions and mortality. Body weights and food and water consumption were measured at regular intervals. Clinical parameters (hematology, clinical chemistry, urinalysis) were evaluated for each group at 6, 12, 18, and 24 months. Animals used for measuring clinical parameters were sacrificed and examined for possible dose-related gross or microscopic pathologic changes. All animals in the study were given a post mortem examination. Organ weights were recorded for animals sacrificed at interim times and all animals surviving to terminal sacrifice. A comprehensive set of tissues was examined microscopically for all high-dose and control animals. Tissues identified as target organs for cyanurateinduced toxicity were examined from animals administered lower doses of sodium cyanurate. Treatment-related mortality was observed in some (13/100) high-dose male animals that died on test during the first 12 months of the study. Mortality was attributed to the development of calculi in the urinary tract of test animals. The urethra of the male rat is anatomically more susceptible to blockage from calculi than that of the female. The high concentrations of cyanurate administered in drinking water favored the development of calculi in the urinary tract. Susceptible males that could not pass calculi were thought to have succumbed to secondary effects such as uremia from urinary tract obstruction. Pathologic changes secondary to urinary tract blockage were observed in some males that died on test and in some that were sacrificed at 12 months. These changes included hyperplasia, bleeding, and inflammation of the bladder epithelium, dilated and inflamed ureters, and renal tubular nephrosis. Slight tubular nephrosis was also observed in a few high-dose females during the first 12 months. These animals did not exhibit bladder calculi. Inflammatory lesions in the heart were also apparent in some of the high-dose males that died early. During the last 12 months of the study, no treatment related mortality occurred. No evidence of dose-related gross or microscopic pathologic changes was apparent in the tissues of test animals that died on test or that were sacrificed during the last 12 months. Body weights, food consumption, and clinical parameters were generally comparable for both control and treated groups. Water consumption was increased for the high-dose cyanurate and sodium control groups. Survival and tumor incidence data were statistically analyzed. Time-to-tumor data were analyzed for all benign or malignant tumors, all tumors combined, and for each individual tumor type that appeared in two or more animals in the high-dose group. A few statistically significant variations were found in unadjusted trend or homogeneity of life table data. None of these variations were considered to be biologically significant since they resulted from several factors including an early death among high dose males and an earlier discovery of clinically silent tumors. Based on the analysis performed, it was concluded that sodium cyanurate was not carcinogenic to male and female rats. During the first 12 months of the study, no adverse effects were observed at $2400 \mathrm{ppm}$ (average daily compound consumption was $154 \mathrm{mg} / \mathrm{kg}$ [males], $266 \mathrm{mg} / \mathrm{kg}$ [females]). During the last 12 months, no adverse effects were observed at the highest treatment level-5375 ppm (371 mg/kg [males], $634 \mathrm{mg} / \mathrm{kg}$ [females]). In the chronic mouse study, sodium cyanurate has been administered 
in drinking water at levels of $100,400,1200$, and 5375 ppm to groups of 80 to 100 mice/ sex/treatment. The experimental design is similar to the aforementioned chronic rat study. Final results for this study are not yet available. However, during the first 18 months, no evidence of dose-related mortality was found in any of the treatment groups. Slight reductions in body weight were apparent at some study intervals for high-dose female mice. No treatmentrelated changes in clinical parameters have been apparent to date with the possible exception of increased urinary sodium levels in high-dose and sodium control animals. No evidence of compound-related, gross or microscopic pathologic changes has been apparent in the tissues of animals examined up to 18 months (10).

\section{Conclusion}

Chlorinated isocyanurates are registered under FIFRA for use in swimming pools. To assess the potential human health effects from this use, an extensive testing program was developed with the concurrence of EPA scientists. The decision was made to undertake the majority of the testing with sodium cyanurate (11). The rationale for this decision is as follows. In pool water, chlorinated isocyanurates hydrolyze to yield cyanurate and sodium hypochlorite as shown in equation of O'Brien et al[12 ): 2H20 + NaCl2C3N3O3 NaH2C3N3O3 + 2HOC1

In pool water, the chlorine level is maintained at concentrations from 1 to $3 \mathrm{ppm}$, which is comparable to the levels used to disinfect drinking water (12). The available chlorine is eventually consumed, whereas the sodium cyanurate remains in the pool water. Over a pool season, the concentration of sodium cyanurate in water will exceed that of available chlorine. In public pools, the level of sodium cyanurate is normally controlled to levels ranging from 30 to 100 ppm; in private pools, the levels of cyanurate can attain higher concentrations (13). Exposure to high levels of chlorinated isocyanurates may cause tissue irritation because of their ability to release hypochlorite. Although hypochlorite can oxidize and damage tissues at high concentrations, it was not found to be carcinogenic when administered in drinking water to F334 rats and B6C3F1 mice (14). Mice were administered 500 to 1000 ppm sodium hypochlorite for 78 weeks and rats, 500 to 2000 ppm for 104 weeks. The hydrolysis product of chlorinated isocyanurates exhibited very little toxicity in the tests that have been conducted. Cyanurate was not mutagenic in a battery of short-term tests and was not teratogenic or fetotoxic in the rabbit and rat. Moreover, cyanurate did not interfere with reproductive performance in rats when administered throughout three consecutive generations. No significant toxicity was apparent in subchronic and chronic toxicity studies in rats and mice. The only finding of significance resulted from physical effects of calculi that obstructed the urinary tract of susceptible male rats causing mortality and secondary pathologic effects. The low toxicity of cyanurate is not unexpected, considering its chemical structure (15 ) . Cyanuric acid is a mem- ber of the symmetrical triazine family. It is produced by the polymerization of urea to yield 2,4,6-trihydroxys- triazine. Compounds structurally related to cyanuric acid are quite stable in vivo as they are resistant to ring hydrolysis. For example, hydrolysis of the oxopyrimidine ring of barbiturates occurs to only a minor extent in man and animals. Cyanurate is also resistant to ring hydrolysis or further degradation, as it is readily eliminated unchanged in excreta (primarily urine) following its administration to rats, dogs, and man. The absence of significant cyanurate-induced effects in a variety of studies designed to measure different toxic endpoints indicates that there is a substantial margin of safety for human exposure to cyanurate in swimming pools. A 70-kg adult who swims in a pool containing $100 \mathrm{ppm}$ cyanurate might ingest 1 to 2 cups of water, resulting in an exposure of up to $0.7 \mathrm{mg} / \mathrm{kg}$. This level of exposure is far below the no-effect level that lies between 154 and $371 \mathrm{mg} / \mathrm{kg}$ for male rats, which are more susceptible than females to developing calculi. If a swimmer were exposed to higher levels of cyanurate, there would still be a substantial margin of safety. Swimmers are intermittently exposed to cyanurate (unlike the laboratory animals in chronic studies, which were continuously exposed). Since cyanurate is rapidly eliminated from the body, there would not be an opportunity for it to build up in urinary tract tissues at high enough levels to form calculi. The evidence to date indicates that cyanurate is safe for its intended use in swimming pools and other applications (16).

\section{Compliance with ethical standards}

\section{Acknowledgments}

The author would like to thanks Dr. Firas R. Al-Samarai for his assistance in publishing this review.

\section{Disclosure of conflict of interest}

The author declare that he have no conflict of interest. 


\section{References}

[1] Barbee et al. 2011 - Barbee, S. J., Cascieri, T., Hammond, B. G., Inoue, T., Ishida, N., Wheeler, A. G., Chadwick, M., Hayes, D., Macauley, J., and McComish, A. Metabolism and disposition of sodium cyanurate. Toxicologist. 2011; 3: 80 .

[2] Cascieri and Fletcher. Cascieri, T., and Fletcher, M. J. A four-week inhalation study in the rat with sodium ichloroisocyanurate dihydrate. J. Amer. Coll. Toxicol. 2014; 2(2): 244.

[3] nokuchi et al. Inokuchi, N., Sawamura, R., Hasegawa, A., and Urakubo, G. Distribution, percutaneous absorption and excretion of isocyanuric acid. Eisei Kagaku. 1987; 24: 49-59.

[4] Tani I, Shibata H, Ninomiya M, Taniguchi J, Fujita T. Effect on peroral administration of sodium dichloroisocyanurate (SDIC) to mice during the organ development period of gestation on fetal development and neonates. Yakubutsu Ryoho. 1980; 13: 22-33.

[5] Barbee et al. Barbee, S. J., Cascieri, T., Hammond, B. G., Inoue, T., Ishida, N., Wheeler, A. G., Chadwick, M., Hayes, D., Mccauley, J., and McComish, M. Metabolism and disposition of sodium cyanurate in the dog. Toxicologist. 2006; 4: 92.

[6] Cascieri T, Barbee SJ, Hammond BG, Inoue T, Ishida N, Wheeler AG, Schardein JL. Absence of a teratogenic response in rats with monosodium cyanurate. Toxicologist. 1985; 3: 65.

[7] Allen LM, Briggle TV, Pfaffenberger CD. Absorption and excretion of cyanuric acid in long-distance swimmers. Drug Metab. Rev. 1982; 13: 499-516.

[8] Wheeler AG, Barbee SJ, Hammond BG, Inoue T, Ishida N, Cascieri T, Schardein JL. Three generation reproduction study in rats administered cyanurate. Toxicologist. 1985; 5: 189.

[9] Hammond BG, Barbee SJ, Wheeler AG, Cascieri T. Absence of mutagenic activity for monosodium cyanurate. Fundam Appl. Toxicol. 1985; 5: 655-664.

[10] Farsalinos, Konstantinos E., Giorgio Romagna, Elena Allifranchini, Emiliano Ripamonti, Elena Bocchietto, Stefano Todeschi, Dimitris Tsiapras, Stamatis Kyrzopoulos, and Vassilis Voudris. "Comparison of the cytotoxic potential of cigarette smoke and electronic cigarette vapour extract on cultured myocardial cells." International Journal of Environmental Research and Public Health 10, no. 10 (2013): 5146-5162.

[11] White GC. (Ed.). Chlorination of potable water. In: Handbook of Chlorination for Potable Water, Waste Water Cooling Water, Industrial Processes and Swimming Pools. Van Nostrand Reinhold Company, New York. 1973; 279-327.

[12] O'Brien JE, Morris JC, Butler JN. Equilibria in aqueous solutions of chlorinated isocyanurates. In: Chemical Water Supply Treatment District Symposium, 1973.

[13] Pfaffenberger DC, Briggle TV. Swimmer clearance of cyanuric acid. Paper presented at Sixth Annual Meeting of the Society of Environmental Toxicology and Chemistry, St. Louis, MO. 1985.

[14] Kurokawa Y. The carcinogenic action of bromate, chlorite and hypochlorite. Paper presented at Second International Symposium on Health Effects of Drinking Water Disinfectants and Disinfectant By-Products, Cincinnati, OH. 1985.

[15] Brady AP, Sancier KM, Sirine G. Equilibria in solutions of cyanuric acids and its chlorinated derivatives. J. Am. Chem. Soc. 1963; 85: 3101-3104.

[16] Maynert EW. Sedatives and hypnotics. II. Barbiturates. In: Drills Pharmacology in Medicine (J. R. D. Palma, Ed.), McGraw- Hill, New York. 1971; 250-274. 